\title{
SOLIDARIDAD Y FRATERNIDAD. UNA NUEVA CLAVE ÉTICO-POLÍTICA PARA LAS MIGRACIONES
}

\section{Solidarity and Fraternity. A new ethical-political key for migrations}

\author{
Ana Paula Penchaszadeh* \\ Senda Inés Sferco**
}

\begin{abstract}
Resumen. Este artículo se propone analizar desde una perspectiva filosófica y política los debates actuales en torno a la figura del "delito de solidaridad" en Francia, tomando como punto de partida el caso de Cédric Hérrou, procesado y condenado en distintas instancias por haber brindado ayuda a migrantes "sin papeles". Se hará hincapié en la decisión del Consejo Constitucional francés que, en julio de 2018 y en nombre del principio de Fraternidad, dejó sin efecto la figura del "delito de solidaridad" en los casos donde la ayuda brindada se diera por razones humanitarias puras y dentro del territorio francés. Consideramos que este caso tiene un valor ejemplara la hora de pensar los dilemas teóricos así como la potencia ético-política de las migraciones en los órdenes democráticos actuales.
\end{abstract}

Palabras clave: solidaridad; migraciones; política; desobediencia; hospitalidad.

\begin{abstract}
This article aims to analyze from a philosophical and political perspective the current debates around the figure of the "crime of solidarity" in France, taking as a starting point the case of Cédric Hérrou, prosecuted and convicted in various instances for having provided aid to migrants sans papiers. Emphasis will be placed on the decision of the French Constitutional Council which, in July 2018 and in the name of the Fraternity principle, rendered null and void the figure of the "crime of solidarity" in cases where the aid provided was given for purely humanitarian reasons and within of the French territory. We consider that this case has an exemplary value when thinking about theoretical dilemmas as well as the ethical-political power of migrations in the current democratic orders.
\end{abstract}

Keywords: solidarity; migrations; politics; disobedience; hospitality.

Investigadora del CONICET con sede en el Instituto de Investigaciones Gino Germani, Profesora en la Universidad de Buenos Aires (UBA). Buenos Aires, Argentina. E-mail: anapenchas@gmail. com. Orcid: 0000-0002-9260-7509.

** Investigadora del CONICET con sede en el Instituto de Investigaciones Gino Germani, Profesora en la Universidad Nacional del Litoral. Buenos Aires, Argentina. E-mail: senda.sferco@gmail. com. Orcid: 0000-0001-9482-5801. 
La decisión del Consejo constitucional es un llamado a los valores de Francia.

Ella viene a decir que el país no pertenece ni a los nacionalistas ni a la extrema derecha.

Francia no es sólo esto; no es un país cerrado sobre sí mismo, egocéntrico. Francia es "Libertad, Igualdad, Fraternidad", los derechos del hombre, los derechos del niño. Mi lucha es legítima. iMuchas personas me preguntan si tienen el derecho de ayudar a otras personas! iEs grave! Esto las tranquilizará (...) Es tranquilizador poder ayudar a alguien, cualquiera sea su origen, su color de piel, su proveniencia, sin tener que pedirle los papeles o preguntarle cuál es su situación migratoria como si fuésemos policías. La administración vela por el poder de policía, no por el ciudadano. Cuando usted tiene a un ser humano con una dificultad en la puerta de su casa, usted lo ayuda. Eso es la fraternidad.

Cédric Herrou ${ }^{1}$

\section{Introducción}

El 12 de julio de este año se hizo circular el borrador final del Pacto Mundial para las Migraciones seguras, ordenadas y regulares ${ }^{2}$. Un texto decepcionante por dejar de lado importantes demandas de la sociedad civil $^{3}$ y desconocer ciertos estándares migratorios ya alcanzados en algunos países de Suramérica ${ }^{4}$. En medio de la desazón y la desesperanza - dela crisis migratoria de venezolanos, hondureños, salvadoreños y guatemaltecos, de los niños latinoamericanos separados de sus padres y encerrados en jaulas por el gobierno de Trump y, más al Sur, de los retrocesos brutales en materia de derechos humanos en Argentina, otrora pionera por su progresista política migratoria -, esa misma semana, una noticia recorrió el mundo dándonos una tregua a quienes trabajamos en la defensa de los derechos humanos de las personas migrantes: el Consejo Constitucional de Francia declaró la inconstitucionalidad de la figura del "delito de solidaridad", en base al reconocimiento de la Fraternidad como principio constitucional legal y vinculante.

En este artículo analizaremos, desde una perspectiva filosófica y política, los debates actuales en torno ala figura del "delito de solidaridad" en Francia,

\footnotetext{
1 Cf. <https://www.lemonde.fr/police-justice/article/2018/07/06/aide-aux-migrants-mon-combatest-legitime-se-rejouit-cedric-herrou_5327337_1653578.html>.

2 Texto disponible en: < https://refugeesmigrants.un.org/sites/default/files/180711_final_draft_0.pdf>.

3 El borrador no incluyó, entre otros puntos fundamentales, el reconocimiento de la responsabilidad de los Estados frente a la regularización de las personas migrantes que viven en sus territorios, la inclusión del principio de no devolución como regla primera y la prohibición de la detención como mecanismo de control migratorio, entre muchos otros reclamos.

4 Algunas críticas a los lineamientos del Pacto pueden encontrarse en: < https://www.cels.org.ar/web/ wp-content/uploads/2018/02/CELSPactoGlobal.pdf> y <https://www.opendemocracy.net/democra ciaabierta/camila-barretto-maia-diego-morales-raisa-ortiz-cetra/pacto-global-para-las-migraci> .
} 
pues entendemos que tiene un valor ejemplar para pensar tanto los dilemas como la potencia ética y política de una nueva hospitalidad de las migraciones en los órdenes democráticos actuales.

Con este fin, realizaremos, primeramente, una descripción del caso de Cédric Herrou y un examen específico del marco jurídico y legal que ha convalidado la criminalización de la solidaridad hacia los migrantes en Francia. Luego, nos abocaremos a un análisis a nivel de las prácticas sociales, buscando dar cuenta de los modos específicos en que hoy la solidaridad permite crear un campo para una experiencia subjetiva, afectiva, social y política que podría tener un pequeño, pero importante e impensado, lugar en nuestras sociedades neoliberales. La solidaridad, en consecuencia, será puesta en valor, tanto a nivel práctico como teórico, subrayando su capacidad de excedencia respecto de la lógica filosófico-política que reflexiona los términos de la hospitalidad del otro, para probarse hoy como una encarnación política efectiva de nuevos modos 'desobedientes' en nombre de la fraternidad.

\section{El caso de Cédric Herrou y el CESEDA}

"Au nom de la fraternité nous resterons solidaires" ("en nombre de la fraternidad seguiremos siendo solidarios"), tweeteó Cédric Herrou, el 6 de julio de 2018, ratificando con estas palabras una victoria pírrica en el tormentoso escenario global de las migraciones actuales. Este agricultor francés de la frontera francoitaliana había sido condenado con una multa de 1.000 euros y a cuatro meses de prisión por ayudar a más de 250 migrantes sans-papiers a pasar al territorio francés, facilitando su circulación y brindándoles albergue. Su caso se sumaba así al de Pierre-Alain Mannoni, que en 2016 había sido detenido, procesado y condenado a dos meses de prisión por llevar en su automóvil a tres eritreos heridos hasta un hospital de Marsella; al de Martine Landry, de Amnistía Internacional, que había sido detenida en 2017 por haber brindado ayuda a migrantes sin papeles y menores de $\operatorname{edad}^{5}$; $y$ a otras 17 personas que, en 2017, fueron condenadas por ayudar a migrantes en situación migratoria irregular y cuyos casos no tuvieron repercusión mediática. Todos estos procesos fueron llevados a cabo por los tribunales franceses aplicando la figura de "delito de solidaridad" o, más precisamente, de "delito de ayuda a la permanencia irregular" tipificado por el Código de Entrada y de Residencia de Extranjeros y del Derecho de Asilo (CESEDA) bajo los siguientes términos: "Bajo reserva de las excepciones previstas en el artículo L622-4, toda persona que de modo directo o indirecto facilite o intente facilitar el ingreso, la circulación o la permanencia irregular de un extranjero en Francia será castigada con cinco años de prisión y una multa de 30.000 Euros".

Cf. <https://www.amnesty.ch/fr/pays/europe-asie-centrale/france/docs/2018/martine-landry-lacharnement-judiciaire $>$. 
Repasemos brevemente la historia específica del artículo L-622-1 del CESEDA que define la figura de "delito de solidaridad". Su anclaje en el derecho francés tiene origen en el artículo 4 de un decreto adoptado por el gobierno de Daladier, el 2 de mayo 1938. En un contexto de crisis ligado a la cercanía de la Segunda Guerra Mundial, este decreto fue parte de un movimiento global de revisión de las reglamentaciones migratorias existentes en los Estados europeos. En efecto, fue la primera vez que todos los aspectos concernientes al ingreso y a la permanencia de los extranjeros se inscribieron de manera sistemática en el derecho francés. Luego de la Liberación de Francia, la legislación de posguerra sobre los extranjeros conservó este primer decreto, replicándolo textualmente como la Ordenanza Nro. 45-2658 del 2 de noviembre de 1945. Este artículo resistió también la reforma constitucional de 2004, donde quedó codificado como el artículo L622-1 del CESEDA.

Desde un inicio, el campo de aplicación de este artículo se definió de manera muy vasta y ambigua (Müller, 2009), siendo el juez, en última instancia, quien debía decidir cuándo se trataba de una "infracción" o de un "delito", el hecho ayudar a ingresar o a permanecer en el territorio francés. Las penas, a su vez, tampoco se hallaban explicitadas y resultaban muchas veces aleatorias, pudiendo implicar desde el pago de multas hasta el encarcelamiento ${ }^{6}$.

Respecto de los castigos sobre la "ayuda" también es preciso especificar las particularidades de su campo de aplicación y punitividad. El artículo L622-1 establece penas para estas conductas independientemente de que sean en grado de tentativa de ayuda al ingreso y/o a la permanencia; la ayuda puede ser directa o indirecta y, en ambos casos, aquí es considerada un delito. Ahora bien, en materia de derecho penal, la ayuda, dícese "la complicidad indirecta" y "la tentativa de complicidad", son generalmente refutadas por la doctrina y la jurisprudencia; a su vez, la jurisprudencia francesa enseña que solo hay delito si la "ayuda" se vincula al acometimiento de otro delito. Sólo en este último caso la punición de la solidaridad podría justificarse en función de un motivo de interés general particularmente fuerte, aludiendo a la afectación de la "seguridad interior" o del "bien común". Por otro lado, sólo la ayuda brindada frente a un peligro actual o inminente para salvaguardar la vida o la integridad física de un extranjero dentro del territorio, probaría la inaplicabilidad de la pena (L622-4 del CESEDA). Por fuera de este amparo de justificación, el campo de aplicación del artículo L622-1 del CESEDA sigue siendo ubicuo, mismo luego de las modificaciones introducidas en el CESEDA a fines de 2018, debido al carácter excepcional de su formulación legal.

\footnotetext{
6 Remarquemos, a su vez, que hasta la ley del 29 de octubre de 1981, la permanencia irregular en el territorio francés era considerada una simple contravención, es decir, no representaba un delito.
} 
Recordemos en este punto, articulando el discurso jurídico con las perspectivas de la filosofía política, que la excepcionalidad es la modalidad propia de un ejercicio soberano que construye fronteras mediante el "extrañamiento" de los no nacionales y a través de una con-fusión permanente entre derecho y violencia, tanto a nivel de las fronteras internas como de las fronteras externas. De ahí que, autores como Étienne Balibar, por ejemplo, hayan insistido en el carácter no democrático de las fronteras de las democracias, mostrando cómo el estado de derecho se diluye en los lugares de "pasaje y tránsito"(Balibar, 2013). Basta mirar en este punto la excepcionalidad que -con el supuesto objetivo de resguardar la "seguridad pública" y el "bien común"- envuelve hoy la gestión de las migraciones en las democracias más consolidadas del planeta para tomar conciencia de este pathos soberano horadando sistemáticamente los estándares mínimos de derechos y garantías.

Ciertamente, la aplicación creciente del CESEDA permite constatar que el principal objetivo de las políticas migratorias actuales es la "lucha contra la inmigración ilegal" (Carrère, Baudet, 2004, p. 4), poniendo el foco en el control de las fronteras nacionales y no en la integración ni en la búsqueda de soluciones duraderas basadas en el respeto incondicional de los derechos humanos. La premisa de las políticas migratorias actuales es que allí donde hay personas moviéndose entre países hay un "problema de seguridad", de ahí que sus palabras preferidas sean "tráfico", "trata" y "terrorismo" (este último vocablo, sintetizando y difiriendo hoy todos los miedos hacia un supuesto "afuera"). El enfoque securitario busca debilitar la visión de la migración como derecho humano y profundizar las imágenes de la usurpación, la amenaza y el des-derecho, enmascarando así la pérdida de capacidad soberana de los Estados nacionales para dar una respuesta democrática, solidaria y hospitalaria a los problemas que los aquejan. No ha de sorprendernos, entonces, que los Estados pongan en marcha dispositivos tales como el "delito de solidaridad", pues deben hacerse de otros instrumentos que estén en grado de "colaborar" con la tarea que no llegan a contener soberanamente: sostener un orden incluyente y "exclusivo" para sus nacionales. Es preciso conmover el ámbito de la vida pública a fines de efectivizar el poder (y la violencia) de una fuerza de ley contra la inmigración, cuya eficacia político-electoral es a viva luz innegable. Pero, aun si los efectos de esta "alergia migratoria" dinamizan hoy aparentemente el único "cálculo soberano" posible capaz de agregar voluntades en contextos neoliberales, engrosando así las filas de una derecha xenófoba, cabe preguntarse por otras formas políticas de relación con el otro que hoy tienen lugar, aunque tenue y débilmente. El caso de Cédric Herrou, como tantos otros casos de solidaridad frente a la escalada migratoria, permite sumar otra cuenta posible dentro del cálculo, en apariencia cerrado, de las 
políticas anti-migratorias en el mundo entero: una práctica de solidaridad capaz de exceder el principio nacional al que parecía estar inexorablemente ligada.

\section{Puesta en contexto del caso de Cédric Herrou}

"Si la solidaridad con los extranjeros es un delito, somos todos delincuentes", dice el Manifiesto de Delincuentes Solidarios firmado por más de 650 organizaciones asociativas y sindicatos nacionales y locales en Francia, a comienzos de $2018^{7}$. Este manifiesto, así como la advertencia de la Iniciativa Ciudadana Europea "Nuestros valores están siendo amenazados: demandamos una Europa hospitalaria"8, denuncian la criminalización estatal de ciudadanos europeos, organizados y movilizados en pos de la solidaridad. En efecto, en el contexto de la declarada "crisis migratoria europea", miles de ciudadanos comprometidos y solidarios han sido sancionados con multas y penas de prisión por brindar ayuda a migrantes (de hecho refugiados), que huyen de todo tipo de violencias. Según estos autodenominados "delincuentes solidarios", sus actos lejos de traicionar una máxima del derecho, son el reflejo de tradiciones europeas de humanidad y generosidad que deben ser reconocidas y protegidas en tanto tales:

¿Sabía usted que la solidaridad es considerada un delito? Ofrecer una comida, comprar un billete de tren o simplemente socorrer a una persona extranjera necesitada, son actos pasibles de una sanción o pena de prisión en 12 Estados miembros de la Unión Europea (UE). Los ciudadanos solidarios que acuden a ayudar a las personas migrantes son considerados "traficantes", ya que la Directiva Europea, al definir de este modo la ayuda a la entrada, al tránsito y a la permanencia de personas en situación migratoria irregular, permite a ciertos Estados miembro de la UE la posibilidad de castigar la solidaridad. La Comisión Europea se ha negado a revisar esta directiva. iJuntos pongamos fin al delito de solidaridad! ${ }^{9}$

El caso de Herrou, entonces, no es un caso aislado. En la página del GISTI, Grupo de Información y Apoyo de Inmigrantes, se sistematiza el conjunto de decisiones judiciales de los tribunales franceses que, desde abril de 2009, se vinculan al "delito de solidaridad"10, registrando más de una treintena de casos que perfilan un panorama inquietante en relación a la criminalización de los "ayudantes" en este país.

7 Cf. <http://www.delinquantssolidaires.org/le-manifeste>.

8 Esta iniciativa, publicada en mayo de 2018, se encuentra dirigida a la Comisión y al Parlamento europeos con vistas a abolir la figura jurídica de "delito de solidaridad" y apoyar a los ciudadanos y ciudadanas que ofrecen apoyo a personas refugiadas y migrantes sin papeles.

9 El texto de la Iniciativa Ciudadana Europea se encuentra disponible en: <http://www. delinquantssolidaires.org/item/initiative-citoyenne-europeenne-nos-valeurs-menaceesdemandons-europe-accueillante $>$.

${ }^{10}$ Información recuperada de <https://www.gisti.org/spip.php?article1399>. 
Particularmente, en la zona del Valle de la Roya, en la frontera francoitaliana, donde habita el granjero Herrou, el compromiso ciudadano de los locales comenzó a mediados de 2015 para dar respuesta a la afluencia creciente de inmigrantes en la región. La estación de Ventimiglia, en Italia, y la frontera Menton-Garavan, en Francia, son los dos escenarios principales de ayuda humanitaria que comenzó con la expulsión de inmigrantes con necesidades de protección del campo "Presidio Permanente No Borders", en septiembre de ese mismo año. Desde entonces, Francia ha promovido un cierre cada vez más represivo de esta frontera, desencadenando la organización y movilización de los habitantes del Valle de la Roya para brindar ayuda a los migrantes y denunciar esta política. Así, en mayo de 2016, la asociación Roya citoyenne fue reactivada con el objetivo de "defender a los ciudadanos del mundo" $y$, en agosto de 2017, luego de que la Corte de Aix-en-Provence confirmara la condena de Herrou, hubo un pronunciamiento público para expresar su apoyo y compromiso con la causa ${ }^{11}$.

Cédric Herrou fue procesado y condenado en dos instancias. La primera, el 10 de febrero de 2017, por el Tribunal de Gran Instancia (TGI) de Niza, en razón de haber "facilitado la entrada, la circulación y la permanencia irregular de numerosos extranjeros (alrededor de 200) sin permiso de residencia sobre el territorio nacional durante el año 2016"12. En esta primera instancia, su condenase enfocó únicamente en el hecho de haber facilitado la entrada de personas desde Vintimiglia (Italia) al territorio francés. Sin embargo, con respecto a la acusación de haber brindado ayuda a la permanencia y a la circulación dentro del territorio francés, Herrou se benefició dela excepción prevista en el artículo L.622-4 (que exime de pena cuando la ayuda no implica una contrapartida monetaria o de otra índole); en esta oportunidad, el tribunal consideró la ayuda a la circulación como un requisito indispensable para la ayuda a la permanencia. Asimismo, la SNCF (Sociedad Nacional de Ferrocarriles Franceses) había tomado parte civil en esta causa contra Herrou por la ocupación, en octubre de 2016, de un edificio desocupado de esta empresa para albergar a 57 migrantes, de los cuales 29 eran niños. Sobre este punto, Herrou, que había sido acusado del delito de "instalación en reunión sobre el terreno de un tercero sin autorización", fue declarado "inocente" debido a que el Tribunal consideró que la ocupación respondía a un "estado de necesidad". En consecuencia, en esta instancia, su pena fue solo de una multade $3.000 €$ por haber transportado migrantes desde Ventimiglia (Italia) a Francia.

\footnotetext{
11 Ibidem. Cf. TGI de Nice, 10 février 2017, n 16298000008.

${ }^{12}$ Cf. <https://www.gisti.org/spip.php?article1399>.
} 
La segunda instancia tuvo lugar en agosto de 2017. Aquí Herrou fue condenado por la Corte de Apelaciones de Aix-en-Provence, previa apelación de la SNCF al juicio precedente en relación a la ocupación de su edificio. Contrariamente a lo dispuesto por el TGI de Niza, esta corte dispuso que, en relación a la ayuda a la permanencia, mismo si no hubo ninguna contrapartida, el objetivo de esta acción "militante" radicaba en hacer fracasar la aplicación de la legislación migratoria, dejando así sin efecto la excepción prevista en el artículo L.622-4, y condenando a Herrou por el delito de ayuda a la entrada, a la circulación y a la permanencia en todas las situaciones. Asimismo, al tampoco reconocer el aludido "estado de necesidad" respecto de la ocupación del edificio, fue condenado por el delito de instalación sin autorización en el edificio de la SNCF. En resumen, el granjero de la Roya fue declarado culpable y sentenciado a 4 meses de prisión y al pago de una multa de $1000 €$ a la SNCF.

Herrou junto a Pierre-Alain Mannonni, también condenado en segunda instancia por el "delito de solidaridad" por la Corte de Apelaciones de Aix-en-Provence, ejercieron su derecho de defensa y presentaron una "Question Prioritaire de Constitutionnalité QPC" (Cuestión Prioritaria de Constitucionalidad) en el Consejo Constitucional de Francia, solicitando la revisión de los artículos del CESEDA que penalizan la solidaridad y vulneran el principio de Fraternidad garantizado por la Constitución ${ }^{13}$. El Consejo Constitucional de Francia se expidió sobre este asunto, el 6 julio de 2018, acudiendo a la Fraternidad como principio con valor constitucional vinculante. El fallo se basó en una recuperación de la devisa republicana "Libertad, Igualdad, Fraternidad", de la cual se desprendería el ideal de ayudar a otros, con fines humanitarios ${ }^{14}$, sin consideración de su situación migratoria y de su nacionalidad dentro del territorio nacional. La decisión del Consejo, entonces, suspende el "delito de solidaridad", que deviene inconstitucional toda vez que la ayuda a la permanencia de personas en situación migratoria irregular se realizara dentro del territorio francés y sin contrapartida monetaria. Con todo, sigue vigente la penalización de la solidaridad cuando ella implica la ayuda al ingreso en el territorio francés, pues se la considera plausible de atentar contra la seguridad nacional y las leyes que regulan la frontera ${ }^{15}$.

${ }^{13}$ Las QCP pueden ser posadas a lo largo de un litigio frente a los tribunales judiciales y el Consejo constitucional debe declarar si la disposición se ajusta o no a la Constitución. Si la disposición fuera contraria a la Constitución debe ser abrogada.

${ }^{14}$ Resulta importante tener en cuenta que en mayo de 2017, la CNCDH del Consejo Europeo había solicitado al gobierno francés la modificación del artículo 622-1, pidiéndoles sancionar únicamente la ayuda brindada con fines lucrativos. Desde la decisión del Consejo Constitucional de julio 2018, entonces, Francia se hallaría en conformidad con el derecho europeo.

${ }^{15}$ Siguiendo las recomendaciones del Consejo Constitucional, el Poder legislativo francés incluirá meses más tarde importantes reformas en su normativa migratoria: la sanción de la Ley n² 2018778 "Para una inmigración controlada, un derecho de asilo efectivo y una integración exitosa", el 10 de septiembre de 2018; y la sanción de una nueva versión del CESEDA, el 13 de diciembre 


\section{Los "militantes solidarios", los nuevos chivos expiatorios}

El caso de Cédric Herrou resulta paradigmático para comprender las estigmatizaciones discursivas que, en función de la aplicación del CESEDA, se utilizan para acusar a quienes brindan ayuda a los migrantes. En efecto, para fundamentar sus condenas, los Jueces han sostenido que estas personas solidarias no han actuado por "simple voluntad de socorro" ("simple volonté de secours"), sino que se han movido por un "espíritu de rebelión" ("esprit de rébellion"). Sus actos, sentenciaron, "se inscriben en una estrategia militante que busca hacer fracasar la política migratoria impulsada por el Estado"16, lo que los vuelve a todas luces "enemigos públicos". Varias derivas de análisis pueden desprenderse de esta peculiar vinculación entre solidaridad, desobediencia y delito.

Primeramente, el viejo problema del vínculo entre "acción" y "voluntad", confirmado por una diferenciación cívica consuetudinaria entre quienes actúan por "simple voluntad de socorro" ("simple volonté de secours") y quienes, en cambio,"son movidos" por un "espíritu de rebelión" ("esprit de rébellion"). El vitalismo contractualista contenido en estas palabras, que busca situar una diferencia entre "voluntad" y "espíritu movido" arguyendo distintos órdenes de responsabilidad, no sólo buscaría condenar la "rebeldía" sino mostrarla como "espíritu irresponsable", puesto que no tendría ella voluntad (ni por tanto razonabilidad) sobre sus actos. Recordemos que este punto había sido desenmarañado por Foucault, en su estudio de 1975 sobre Les Anormaux, cuando buscaba dar cuenta genealógicamente de la articulación entre infamia y desobediencia en el linaje del salvajismo. A partir de su análisis, se demostraba cómo la invocación normativa acierto "instintito anárquico", se vinculaba a los decires, discursos y afectos que buscaban vincular la rebeldía a una suerte de estado de naturaleza salvaje, es decir, pre-cultural, explicando así la "incorregibilidad" de estos sujetos para la institucionalidad "normal" moderna. Los "anormales", en consecuencia, no sólo estarían justificados de exclusión social por su incapacidad para plegarse a las normas de comportamiento de la cultura, sino, de un modo más radical, por no contar con una ratio que les permita decidir sobre sus actos. Esta estrategia de exclusión de individuos según la operación clasificatoria normal/ anormal, performa a la vez una respuesta afirmativa, intempestiva, rebelde y desobediente. Las tensiones entre prácticas, comportamientos, saberes y afectos, de esta manera, no son sólo objeto de una negación al servicio de un control de policía que tiene al comportamiento "normal" como divisa, sino

de 2018. Partiendo del principio de Fraternidad, la ayuda a la permanencia y a la circulación, con fines exclusivamente humanitarios, ya no constituyen delitos en Francia, a diferencia de la ayuda al ingreso en el territorio francés que sigue siendo plausible de sanción.

${ }^{16}$ Cf. TGl de Nice, 10 février 2017, n 16298000008. 
ocasión de una oportunidad política; tal como nos recuerda Miguel Abensour (1998), esta misma tensión sostiene el valor de la insurrección como potencia de disidencia cívica, fundamental para el permanente trabajo de composición que exige una democracia verdaderamente radical.

En segundo lugar, el problema suscitado por el pasaje de una acción individual "como de quien no termina de saber muy bien qué está haciendo", al señalamiento de una estrategia colectiva impersonal que buscaría atentar contra el Estado. En efecto, la condena de estos actos por considerarlos "militantes" busca desvincular al Estado de toda responsabilidad sobre los hechos. Si se atendiese al registro de condiciones efectivas donde tienen lugar los actos de ayuda, tal como lo expone el investigador del CNRS Pierre-Alain Mannoni que, tal como señalamos, es autor del pedido de Revisión de Constitucionalidad presentado al Consejo junto con Cédric Herrou, sería muy fácil constatar que, "escandalizados por la falta de medios, las personas que brindan ayuda a los migrantes y a los refugiados resultan rápidamente contestatarios, militantes"17. El Estado, así, buscando desasirse de toda responsabilidad estructural, los transforma en "militantes", construyendo con este gesto un "nuevo" chivo expiatorio, y facilitando una conversión del vecino en enemigo. Tal como veremos, con la denominación "militantes" también se abre una dimensión "política" de la insurrección cívica que excederá la dimensión de un acto de desobediencia o de ayuda efectuado a título individual.

Una tercera dimensión problemática estaría, entonces, implicada por la suerte de desplazamiento "identitario" suscitado por los efectos subjetivos y sociales "estigmatizantes" que acarrea el pasaje de la caracterización de individuos "solidarios" a la apelación "militantes". La calificación "militantes" ha generado, de hecho, por parte de los condenados, numerosas reacciones adversas, a veces incluso contradictorias, buscando desenmascarar la operación política detrás de las acusaciones de los Jueces. Por ejemplo, para defenderse de la estigmatización, las declaraciones de Mannoni aludieron a que "el Estado no asume que simples ciudadanos solidarios seamos tratados como militantes"; incluso el mismo Cédric Herrou, dijo que "Los jueces (...) me calificaron de entrada como militante, aun si no formo parte de ninguna asociación y nunca me he reivindicado como tal"18.

Estas declaraciones, que defensivamente desdicen los procesos organizativos de las personas solidarias, en verdad nos permiten dar cuenta de la complejidad de los dilemas ético-políticos que hoy comporta un accionar colectivo y solidario atento a la crisis humanitaria de las migraciones. En efecto, ¿cuándo empezamos a asumir que "militar" causas y formar agrupaciones

${ }^{17}$ Cf. $\quad<$ https://info.arte.tv/fr/delit-de-solidarite-larme-des-politiques-contre-laide-aux-migrants > . Nuestra traducción.

18 Ibidem. 
serían males en sí mismos? ¿Cómo pudo el liberalismo trocar su mejor tradición, su pasión reivindicativa y asociativa, por un desentendimiento de los asuntos comunes?

Ciertamente, la superposición de los estigmas "ciudadanos solidarios" y "militantes" es reveladora de la estrategia de despolitización necesaria para las gubernamentalidades neoliberales que, tal como advertía el diagnóstico foucaultiano, lejos de desentenderse del Estado, disponen de él para introducir aquí y allá, en las figuras y en los afectos más impensados, más individualismo. De hecho, la necesidad de separarse en el orden discursivo de la figura del "militante" también es prueba de la profunda incidencia que, a nivel subjetivo e interpersonal, han logrado las lógicas neoliberales de gobierno, efectuando una estigmatización reiterada de la participación política individual y grupal en la vida pública que, lamentablemente, hoy excede al territorio Francés y hallamos cíclicamente restaurada como política de Estado en nuestras latitudes.

Un punto interesante, al decir de Manonni, es que, en el contexto francés esta estrategia estaría por sí misma generando su contrario: "una verdadera relación de fuerzas está poniéndose en marcha en Francia con los ciudadanos, los representantes, las asociaciones ${ }^{\prime 19}$, puesto que, de un modo claramente contraproducente para sus políticas de Estado, el "absurdo" en el que busca argumentarse "cada nuevo proceso, no hace otra cosa que reforzar las convicciones de los ayudantes y empuja las asociaciones a organizarse mejor"20. Una suerte de "campo solidario" estaría así hoy reforzando su tejido, elaborando y reactualizando prácticas de resistencia.

\section{4. ¿Delito de hospitalidad o delito de solidaridad?}

Atendiendo al sentido filosófico de las palabras que se van imponiendo en este escenario y guían nuestra reflexión, cabe preguntar: ¿sobre qué fundamento político puede considerarse la solidaridad como un delito? Efectivamente, resulta difícil encontrar un absurdo republicano, por no decir humanitario, más expresivo que éste. Pero, ¿dónde radica su consistencia? ¿Qué implicancias tiene la aplicación concreta del CESEDA? ¿Cuál es el delito real que viene a sancionar? Como vimos, la figura del "delito de solidaridad" permite abordar los procesos de penalización directa e indirecta a través de los cuales hoy se nutren los modos de subjetivación vinculados a la hospitalidad del otro y a las migraciones como problema específico de nuestro tiempo. En lo que sigue desarrollaremos las particularidades y diferencias entre "solidaridad" y "hospitalidad", a fines de dar cuenta de la especificidad adjetivante del "delito" que aquí se busca sancionar.

\footnotetext{
19 Ibidem.

20 Ibidem.
} 
Ya a mediados de los años noventa, el filósofo argelino Jacques Derrida denunciaba la sensación de "cierre de pecho" ("souffle coupé") y de "golpe al corazón" ("haut le coeur") que le provocaba la expresión "delito de hospitalidad" ("délit d'hospitalité").

(...) lo leí sin voz en un texto oficial. Se trataba de una ley que permitía perseguir, incluso, encarcelar, a aquellos que den acogida y ayuda a extranjeros en situación considerada "ilegal". Este "delito de hospitalidad" (todavía me pregunto quién ha podido osar asociar estas palabras) es pasible de encarcelamiento. ¿Qué deviene un país, nos preguntamos, qué deviene una cultura, qué deviene una lengua cuando puede hablarse de "delito de hospitalidad", cuando la hospitalidad puede tornarse, a los ojos de la ley y de sus representantes, un crimen? (Derrida, 1997, p. 73-74)

Para aquellos que estamos familiarizados con el pensamiento derridiano en torno a la hospitalidad, resulta un tanto extraña la "sorpresa" de Derrida. En efecto, la pregunta "¿cómo es que la hospitalidad pudo tornarse un crimen a los ojos de la sociedad francesa?" entraña un punto paradójico caro a las propias reflexiones de este autor: la hospitalidad del otro implica siempre un acto de transgresión de las leyes de la comunidad política que dan forma a su adentro/ afuera y, por lo tanto, siempre es "resentida" por el soberano.

En su texto La hospitalidad (Derrida, Dufourmantelle, 2000), el filósofo elige la figura paradigmática de Antígona para tematizar una Justicia siempre en excedencia respecto del derecho ${ }^{21}$ : las Leyes no escritas trascienden las leyes de la pólis, y la hospitalidad incondicional no puede más que darse como transgresión de las leyes particulares que buscan regular y reglar la llegada de los extranjeros, los no nacionales, "esos" que a priori parecen "indignos". No debería sorprendernos, entonces, que la hospitalidad pueda volverse eventualmente un "delito" a los ojos del Estado, pues entraña un acto de desobediencia de las leyes positivas en nombre de ciertas leyes superiores y no escritas de la humanidad basadas en el reconocimiento de la "dignidad" del otro. Este respeto de la dignidad que funda una antigua tradición será recepcionada por el Derecho Internacional de los Derechos Humanos, después de la Segunda Guerra Mundial.

Balibar (2002), por su parte y contemporáneamente a los dichos de Derrida, también se inspirará en la figura de Antígona para referir a cierta excedencia subjetiva y política que moviliza la desobediencia frente a la Ley. En referencia a una petición lanzada por un grupo de realizadores cinematográficos contra la ley "Debré"22, bajo la consigna "hemos acogido y

\footnotetext{
21 "Faltas del derecho a la Justicia", se titula la conferencia publicada en 1997 a la que estamos haciendo referencia desde el comienzo en este artículo.

${ }^{22}$ Esta ley (de 1997) obligaba a toda persona anfitriona ("hébergeant") a declarar en la policía la llegada y la partida de extranjeros en situación "irregular".
} 
seguiremos acogiendo en el futuro a extranjeros en situación documentaria 'irregular' en el territorio nacional", Balibar definirá en estos términos la desobediencia cívica: "No solo se trata de individuos que, conscientemente, objetan la autoridad. Sino de ciudadanos que, en circunstancias graves, recrean su ciudadanía mediante una iniciativa pública de 'desobediencia' al Estado" (Balibar, 2002, p. 17).

Ahora bien, la referencia derridiana a la expresión "delito de hospitalidad", que refiere al CESEDA, no puede dejar de plantearnos la pregunta acerca de su proximidad o distancia respecto de la otra expresión, más actual, que atraviesa el caso que aquí analizamos: "delito de solidaridad". En efecto, cuando hablamos de "hospitalidad" y de "solidaridad", inos referimos a una misma cosa? ¿Puede decirse que ambas nominaciones implican similares modos de relación con el otro? ¿Prácticas comparables? ¿Qué estatuto social revisten ambos vocablos? ¿Vienen uno y otro término a señalar un mismo modo de "desobediencia cívica"? En un contexto de consolidación del enfoque securitario, donde las fronteras se han transformado en nuevas cortinas de hierro ("rideaux de fer") (Derrida, 1997, p. 74) y el Mediterráneo en una gran fosa común, ¿qué relevancia tiene la transición, en las formas del decir, de la figura "delito de hospitalidad" a la figura de "delito de solidaridad" en Francia?

Podemos decir que la hospitalidad supone un cierto reconocimiento de la extrañeza/extranjería del otro-otro: un anfitrión, un huésped, un cierto orden vertical, una frontera y también, obviamente, la con-fusión eventual, siempre posible, de ambos y de todos estos elementos. La solidaridad, en cambio, supone una repartición horizontal, un escenario de "iguales" y no ya, siguiendo la definición que nos ofrece Todorov (2004) en Frente al límite, una entente signada por la diferencia. Así, la solidaridad, entendida como práctica de reciprocidad social hacia aquellos que se consideran como iguales, no solo ha de diferenciarse de la hospitalidad - siempre marcada por una frontera, una llegada, un recibimiento, una extrañeza - sino también de otras prácticas, como ser: la caridad, que se ofrece al absolutamente desigual y el cuidado, que se profesa a los de la propia familia. Aun si no podemos detenernos aquí en un análisis pormenorizado de cada una de las dimensiones de estos términos, su mención permite dar cuenta de cierto espectro conceptual y semántico del decir, en el cual se tematiza la ayuda desinteresada que brindamos a otros, en tanto otros, en nuestras sociedades contemporáneas.

De esta manera, "hospitalidad" y "solidaridad" balizan de algún modo el campo de prácticas y vínculos sociales abocados a dar cuenta de los modos de acción política en relación con el otro que se hallan impulsados por la obligación ética de responder a aquel que sufre aquí y ahora. En el terreno demarcado por la hospitalidad, todavía hay chez-moi, anfitrión, huésped, frontera; la tensión hostilidad/hospitalidad está contenida en su fragua "vertical"; el punto 
de partida y de llegada es la extrañeza radical, deriva trágica, primero, de la diferencia del otro y, segundo, del sí mismo como otro. Por el contrario, en el espacio abierto por la solidaridad, la frontera se haya diluida al interior de un orden (o desorden) común, de ahí que se pueda apelara la ficción de una fraternidad extensa, desligada del nacimiento (desligada entonces también de la Nación), frente aquel que sufre, cualquiera sea éste. Esta diferencia nos permite entonces hipotetizar que, tal vez, en base a esta transición en apariencia nimia de la hospitalidad a la solidaridad, cierta interpretación nueva del "principio de fraternidad" (parte inescindible de la trilogía republicana francesa, "Liberté, Egalité, Fraternité") haya tenido parte en un proceso histórico de transmutación de prácticas sociales. Tal vez este desplazamiento de la hospitalidad a la solidaridad, perceptible tanto en las formas del decir como a nivel de las prácticas, haya permitido dejar de cifrar al otro como extranjero para posicionarlo, en cambio, como hermano-fratelo. Tal vez esta transformación experiencial del campo solidario, explicaría la declaración de inconstitucionalidad por parte del Consejo Constitucional de Francia del delito de solidaridad, en base al principio de Fraternidad.

\section{A modo de conclusión}

Tal como hemos analizado hasta aquí, "delito de solidaridad", es una expresión que por sí misma performa una turbación que no sólo radica en la construcción ionesquiana de sus términos, sino en los efectos concretos que implica a nivel de las prácticas sociales e individuales. En efecto, "delito de solidaridad" apunta a una producción de subjetividad particularmente específica basada tanto en el temor a la Ley - según Kafka, uno de los afectos constitutivos del derecho -, como en el desaliento del lazo social: es necesario diseminar la amenaza en la vida pública, que los ciudadanos adhieran a la visión del migrante como individuo peligroso, que no tenga sentido ayudarlo, o en todo caso, que sea demasiado costoso, que implique un sacrificio, un castigo por osar portar, como Atlas en sus espaldas, una situación de emergencia mundial que la "humanidad" ya no puede cotejar. "Alojarlos en nuestras casas, darles de comer, prestar o darles dinero, informaciones útiles... i Hasta dónde? ¿Dónde se detiene el delito de ayuda a la entrada y la permanencia de los irregulares?" (Carrère, Baudet, 2004, p. 12. Nuestra traducción).

Hoy la crisis migratoria ha tomado una dimensión tan alarmante a nivel mundial que ser "solidario" devino un delito. Es preciso desalentar los actos de solidaridad, estimular el silencio y la apatía. Es preciso que "el ciudadano común" participe por acción u omisión, en la cacería de los sin papeles que amenazan su con-vivencia. Esta modalidad persecutoria y colaboracionista, reactualiza una metodología criminalizadora del otro que Europa ya vivió (ieste decreto devenido ley es de 1938, a no olvidar!), no hace tanto tiempo, 
cuando fomentaba la práctica de la sospecha y de la denuncia entre vecinos como política de Solución Final ${ }^{23}$. No estamos aquí estableciendo una correspondencia de derecho - mismo si vimos que el artículo del CESEDA ha quedado intacto desde 1938 -, tampoco una correspondencia de hecho - ya que la situación socio-histórica no es la misma -, pero sí de método, puesto que se hace recurso a estrategias discursivas y no discursivas similares a la hora de incidir a nivel de las prácticas, y a fines de producir una subjetividad temerosa y criminalizadora del otro que llega. La caracterización condenatoria de la solidaridad intenta consolidar el peor de los escenarios para las causas comunes y justas: "ocúpate solo de tus asuntos", "à tes affaires". En este sentido, la desobediencia cívica de franceses para acoger a migrantes sin papeles, de alguna manera, es la otra pieza "imprevista" que completa actualmente el cuadro de la experimentación democrática frente a las migraciones. También, la apelación al principio de Fraternidad, como principio vinculante capaz de reponer cierta esfera de derechos en nombre de una "humanidad" que todavía busca recomponer sentido desde sus restos. Tal vez sea esta la potencialidad escondida del concepto de Fraternidad (Kristeva, 1988) que, en su capacidad de excedencia puede venir a recordar la importancia de sus compañeras, la Libertad y la Igualdad, en un mundo que parece haber olvidado que migrar es un derecho humano.

Mientras cerramos este escrito, nuestra región también comienza a dar signos de esta aún débil "autonomía" de los ciudadanos solidarios rebelándose contra toda política restrictiva e incluso contra todo posicionamiento estatal. Los dejamos con el testimonio reciente, del 24 de octubre de 2018, de un mexicano solidario de la localidad de Escuintla, Chiapas, dirigido a los refugiados hondureños de la Caravana Migrante.

Hoy estamos aquí reunidos, todos los hermanos con el firme propósito de ayudar a la Caravana Hondureña que viene con muchísima necesidad. Hoy no somos habitantes de ningún un lugar, hoy somos simplemente habitantes del mundo. El propósito es ayudar a quien más lo necesita con la firme convicción de que la humanidad no puede tener barreras. La humanidad somos todos ${ }^{24}$.

\section{Bibliografía}

ABENSOUR, Miguel. La democracia contra el Estado. Buenos Aires: Colihue, 1998. BALIBAR, Étienne. Les frontières de la démocratie. Paris: La Découverte, 2013.

BALIBAR, Étienne. Ciudadanía. Buenos Aires: Adriana Hidalgo, 2012.

BALIBAR, Étienne. Droit de cité. Paris: PUF, 2002.

\footnotetext{
${ }^{23}$ Tal como documentan los trabajos de reapertura de archivos recientemente realizados por Wieviorka y Jablonka (2017).

${ }^{24}$ Cf. <https://twitter.com/AmnistiaOnline/status/1055149000654012419>.
} 
BALIBAR, Étienne; WALLERSTEIN, Immanuel. Race, nation, clase. Les identités ambiguës. Paris: La Découverte, 1997.

CARRÈRE, Violaine; BAUDET, Vèronique. Délit de Solidarité. Pleindroit, n. 59-60, mars 2004.

DERRIDA, Jacques. Canallas. Dos ensayos sobre la razón. trad. de C. de Peretti. Trotta: Madrid, 2005.

DERRIDA, Jacques; DUFOURMENTELLE, Anne. La hospitalidad. Buenos Aires: La Flor, 2000.

DERRIDA, Jacques. Manquements du droit à la justice (mais que manque-t-il donc aux "sans papiers"?). In: DERRIDA, Jacques; GUILLAUMME, Marc; VINCENT, Jean-Pierre (eds.). Marx en jeux. Paris, France: Descartes \& Cie, 1997.

FOUCAULT, Michel. Les anormaux. Cours au Collège de France 1974-1975. Paris: Seuil Gallimard, 1999.

JABLONKA, Ivan; WIEVIORKA, Annette (comps.). Nuevas perspectivas sobre la Shoa. UNQ: Bernal, 2017.

KRISTEVA, Julia. Étrangers à nous-mêmes. Paris: Folio, 1988.

MÜLLER, Olivia. La pénalisation de l'aide au séjour irrégulier: De la volonté politique à la réalité judiciaire. Mémoire de Master 2 Sous la direction de Manlio Cinalli. Institutd'études politiques de Paris Master Recherche "Politique et sociétés en Europe". Politiques Publiques, 2009.

PENCHASZADEH, Ana Paula. Política y Hospitalidad. Disquisiciones urgentes sobre la figura del extranjero. Buenos Aires: EUDEBA, 2014.

TODOROV, Tzvetan. Frente al límite. Madrid: Siglo XXI, 2004. 